\title{
THE IMPLEMENTATION OF FUZZY-TSUKAMOTO METHOD IN MAKING THE BEST DECISION TO BUY A SMARTPHONE
}

\author{
Adwitya Rai Paramaartha ${ }^{1}$ \\ Rikip Ginanjar ${ }^{2}$ \\ President University, \\ Cikarang, Bekasi , Indonesia \\ 1araipars@gmail.com \\ rikipginanjar@president.ac.id
}

\begin{abstract}
Smartphone is one of the most important things for people nowadays. The increasing number of products as well as the amount information carried by each brand of smartphone can overload, there are many things to consider before buying a smartphone. Fuzzy logic is a form of many- valued logic in which the truth values of variables may be any real number between 0 and 1. Fuzzy logic is one method to analyze system containing uncertainty. This study aims to use fuzzy logic in helping people make decisions on buying the most suitable smartphone for them by producing an output value that can help the user to determine which smartphone will be purchased based on user's ideal criteria of a smartphone.
\end{abstract}

\section{Introduction}

Smartphone has become a part of human daily needs. In real sense Smartphone is a mobile phone with advanced features and functionality. Most people that do not keep in touch with current technology advancement usually do not know what kind of smartphone is actually suitable for them. The increasing number of products as well as the amount information carried by

each brand can overload, also many things to consider before buying a smartphone. Due to various things like that, potential customers are often confused to choose, and it will lead to sub optimal decision and finally they will regret their decision.

A decision support system (DSS) is an information system that supports business or organizational decision making activities. DSSs serve the management, operations and planning levels of an organization (usually mid and higher management) and help people make decisions about problems that may be rapidly changing and not easily specified in advance.[2 ]

The Fuzzy Inference System (FIS) Tsukamoto method is a popular paradigm for undertaking assessment / measurement and decision problems.

The main objective of this thesis is to create a web based application that is able to help people decide which smartphone is best for them based on their ideal criteria using Fuzzy Inference System Tsukamoto Method.

\section{Limitation}

This thesis is focused on developing a web based application for people who needed help on choosing the best or most suitable smartphone for them by inputting the specification of each criteria value needed by the application based on the user's need. The Input from the user itself will later be processed by Fuzzy Inference System

(FIS), Tsukamoto Method and produce an output of numbers that will rank the smartphones to represent the most suitable smartphone for the user. The Fuzzy Inference System can also be used to help made decision in other things as well. In this thesis, the method is being used to make decision in choosing smartphone.

\section{Methodology}

In obtain the Overall Score of a smartphone so that it can represent how good a smartphone is. The following three stages of FIS Tsukamoto, which are Fuzzification, Inference and Defuzzification: as shown in figure 1 . 


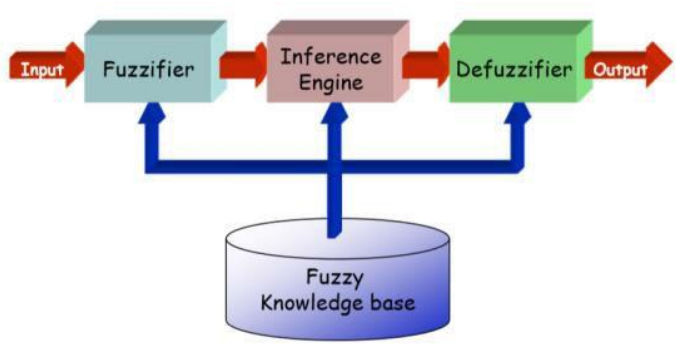

Figure 1. Fuzzy Inference System Architecture [1] [8]

1. Fuzzification

Fuzzification is the processs of converting a non-fuzzy variables (numerical variables) into a fuzzy variables (linguistic variables)[2] [9]. The variables that will be used must be defined first, such as variable demand, inventory and production. Each variable has a fuzzy set. For example in a Membership function there is High and Low, and the degree of truth is shown in figure 2



Figure 2. Membership Function

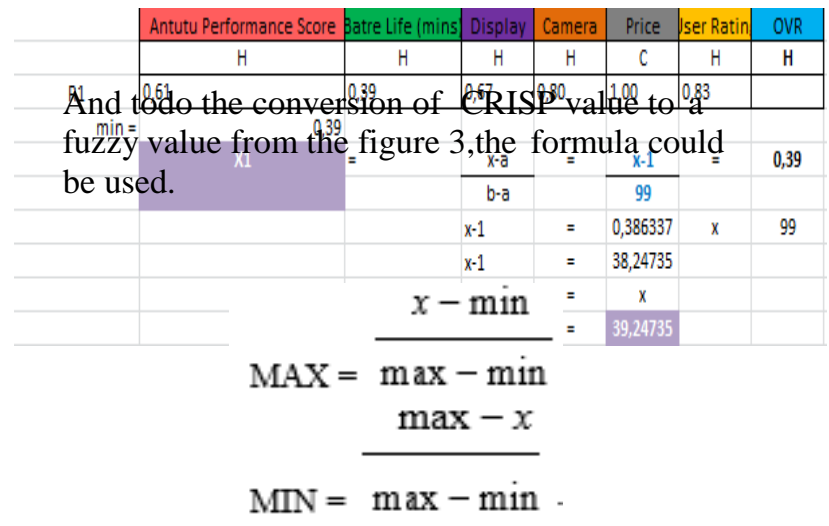

Figure 3. Fuzzification Formula

From the graph in figure 2.5 and 2.6, a conclusion could be drawn if a smartphone 's overall score is 70 , it is considered as $70 \%$ High and $30 \%$ Low. As described in figure 4.

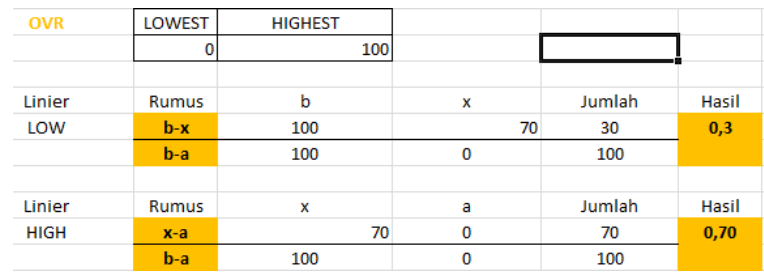

Figure 4.

2. Inference

Inference is the process of combining many rules based on available data. Fuzzy inference system receives input crisp. This input is then sent to a knowledge base that contains $\mathrm{n}$ fuzzy rules in the form of IF- THEN.

The general form of the rules used in the implication function are:

IF $\mathrm{x}$ is A THEN $\mathrm{y}$ is $\mathrm{B}$

With $\mathrm{x}$ and $\mathrm{y}$ are scalars, and A and B are fuzzy sets. Proposals that follow IF are referred to as antecedents, whereas propositions that follow THEN are referred to as consequences. The ideal number of rules used in a fuzzy inference system is the amount of sub-criteria to the power of amount of criteria, for example if a system has 2 sub criteria, (High \& Low) and 6

Criteria (A,B,C,D,E,F) there will be $2^{6}=64$

Rules used. In inferenced system, a collection of $\alpha$ and $Z$ values will be taken and it is shown by figure 5.. The amount of $\alpha$ and $Z$ will be the same as the amount of rules

Figure 5. Inference Process After all the $\alpha$ and $\mathrm{Z}$ are generated the

process could proceed to the next step of the Fuzzy Inference System which is Deffuzification.

3. Defuzzification

Determine the crisp output value will be the number of goods produced ( $\mathrm{Z}$ ), by changing the input (in the form of fuzzy sets derived from the composition of fuzzy rules) into a number of 
fuzzy sets in the domain.

Defuzzification method used in the Tsukamoto method is centered average method and it shown by figure 6 .

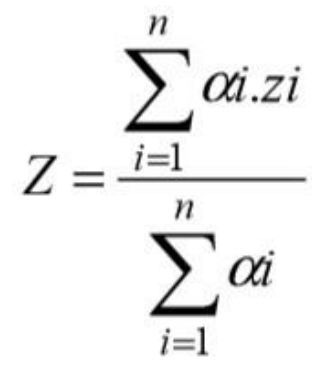

Figure 6. Defuzzification Formula [3] [6]

After all the $\alpha$ and $\mathrm{Z}$ values are generated from the inference process, the calculation that is shown in figure 6 can be performed, the $Z$ value will represent the overall score of a smartphone, ranged from 0-100



Figure 7. Process

\section{Experimental Results}

Testing is a detailed, comprehensive quality assurance process to ensure the whole application runs well according to its scope and limitation. This includes finding bugs / errors and making sure the application fulfills its requirements. There are three sections that will be described, which are Testing Environment, Testing Scenario and Accuracy.

\section{- $\quad$ Testing Environment}

The application is tested using the hardware and software listed below. Testing is done on all possible scenarios. Environment specification is as follows.

1. Microsoft Windows 1064 - bit operating system

\section{6 GB of RAM memory NVIDIA $820 \mathrm{~m}$ GTX}

3. Visual Studio Enterprise 2017

4. XAMPP

5. Mozilla Firefox

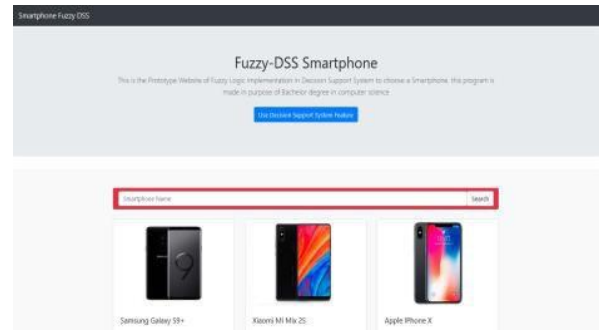

Figure 8. Home Page User Interface



Figure 9. Parameter Input Page User Interface

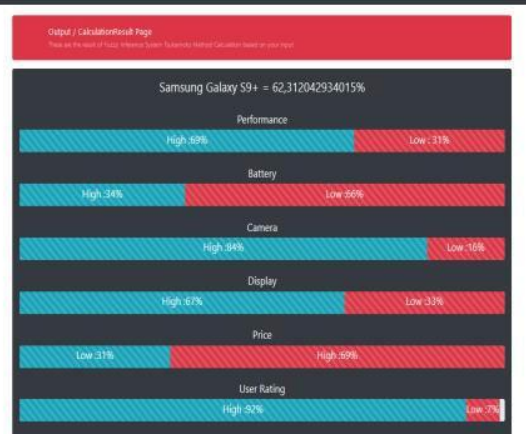

Figure 10. Output Page Calculation Detail User Interface

- Result Accuracy

Testing Accuracy is intended to ensure the Fuzzy Inference System algorithm works as calculated and does not contain bugs or errors.and it shown by table 1 . 


\section{Conclusion}

the Implementation of Fuzzy Inference System Tsukamoto method in determining the most suitable smartphone itself works as expected. But to be published in society the website needs a lot more Smartphone data so that it is helpful for people. produce several conclusions.

1. Fuzzy Logic can be considered as one of Decision Support System methods

2. Fuzzy Inference System Tsukamoto could be implemented in not only to make decision about smartphones but also other things as well.

3. The more criteria used in a Fuzzy Inference System, the more rules it should have, and the more precise the decision output will be.



\section{References}

[1] Abdul ,Talib Bon ; Silvia, Firda Utami (2014).

Analytical Hierarchy Process and Fuzzy Inference System Tsukamoto for Production Planning. International Trade \& Academic Research Conference (ITARC) 3rd -4th November 2014, London-UK

[2] Frans Susilo, S.J. 2006. Association and Blurred Logic and Its Application. 2nd Ed. Yogyakarta: Graha Ilmu.

[3] Kusumadewi,Sri;Purnomo;Hari(2010)"Aplikasi Logika Fuzzy untuk Pendukung Keputusan" [5] Novák, V., Perfilieva, I. and Močkoř, J. (1999)
Mathematical principles of fuzzy logic Dodrecht: Kluwer Academic 91

[4] F. Burstein; C. W. Holsapple (2008). Handbook on Decision Support Systems. Berlin: Springer Verlag.

[5] Fowler, Martin(September 25th,2003). UML Distilled: A brief Guide to the Standard Object Modeling Language (3rd Edition)

[6] Jain,Rajni (2016). Decision Support Systems: an Overview

[7] Keen, Peter; (1980),"Decision support systems : a research perspective."Cambridge, Massachusetts : Center for Information Systems Research, Alfred P. Sloan School of Management.

[8] Shang,Kailan;Hossen,Zakir (2013),"Applying Fuzzy Logic to Risk Assessment and DecisionMaking"

[9] Sparks, Geoffrey(2010), "Database Modeling in UML". 